\title{
EFFECT OF HYPERVITAMINOSIS "D" ON THE OVARIES OF THE ADULT ALBINO RAT
}

\author{
By \\ Amira Ibrahim Hasan, Al-Motasem Bellah M. Al-Sherif, \\ Medhat M. Morsy and Hanan Dawood Yassa \\ Anatomy Department, Faculty of Medicine, Cairo University
}

\section{INTRODUCTION}

Although vitamin " $D$ " is typically classified as a fat soluble vitamin its active form in the body acts as a hormone (James and Otto, 1975). The importance of vitamin "D" in calcium and phosphorus metabolism was previously explained by many research workers. Braidman and Anderson (1985) stated that in addition to the known target organs for vitamin "D", specific receptors for vitamin D (VDRs) were detected in a number of other tissues, namely: skin, pancreas, lymphocytes and reproductive organs as the testis, ovary and uterus suggesting a wider spectrum of vitamin "D" biological effects.

Many observations indicated that vitamin " $\mathrm{D}$ " plays an important role in the female reproductive system. Kumar et al. (1979) found that the circulating level of vitamin "D" was raised at the time of ovulation and during pregnancy and diminished in the postmenopausal state.

The effect of hypervitaminosis " $\mathrm{D}$ " on the female reproductive organs of albino rats was studied by Nebel and Ornstein (1966) who detected impaired ovulation and, later on, fertilization on those rats. The ovaries of the treated animals revealed rare mature Graafian follicles and marked increase in the number of atretic follicles.

However, Uchiyama et al. (1996-a) carried out a study on the reproductive effects of hypervitaminosis " $\mathrm{D}$ ". They did not record any changes in the parameters of the female reproductive performance.

Many investigators pointed out that vitamin " $\mathrm{O}$ " can be used in high doses, in dose dependant manner, as a chemotherapeutic agent against many malignant cell lines such as squamous cancer growth (Papavasiliou et al., 1995), prostate cancer (Fife et al., 1997), acute myeloid leukemia (Funato et al., 2002) and thyroid cancer (Liu et al., 2002).

In addition, Vieth (1999) reported that vitamin " $D$ " is used in high doses (10 times more than the normal known daily requirement) as a che- 
moprophylactic agent against cancer breast for women during the child bearing period.

In mice, vitamin "D" is shown to counteract autoimmune disorders like diabetes mellitus, systemic lupus erythematosis, autoimmune encephalitis and rejection of transplants (Meehan and DeLuca, 2002).

Murray et al. (1988) observed that hypervitaminosis "D" can occur in a patient treated by multivitamins drug which contain vitamin "D" if these patient is exposed to the ultraviolet rays of sun as these rays stimulate endogenous formation of vitamin " $\mathrm{D}$ " in the body.

The aim of this work was to demonstrate the effect of hypervitaminosis "D" on the ovaries of the adult female albino rat and to find out whether these effects are reversible or not.

\section{MATERIALS AND METHODS}

Sixty- five adult female albino rats, weighing between $180-220 \mathrm{~g}$. were used in this study. The animals were divided into three groups: one control group, and two experimental groups.

\section{Control Group:}

It consisted of five rats. They were sacrificed after seven weeks at the end of the experiment.

\section{Treated Group:}

It consisted of 30 rats which were injected intraperitonealy with successive doses of vitamin "D3" (12000 IU each) (Horii et al., 1992). The rats were further divided into three equal subgroups: $A, B$ and $C$ according to the number of doses.

Rats of subgroup A received two doses one week apart, rats of subgroup $B$ received a total of three doses one week apart between each two doses while rats of subgroup $C$ received four doses one week apart between each two doses. All the rats were sacrificed one week after the last dose, which is the time required for vitamin "D" to produce its effect as mentioned by Vieth (1999).

\section{Recovered Group:}

It consisted of 30 rats which were divided into three subgroups: $A, B$ and $C, 10$ rats each. Rats of each subgroup were given vitamin "D3" in doses similar to the corresponding treated subgroups but they were sacrificed four weeks after the last given dose in all subgroups since the me- 
tabolism of vitamin " $\mathrm{D}$ " needed three weeks to be completed (Holick and Adams, 1998).

All rats were supplied by a nutritious commercial diet rich in calcium.

They were maintained on a light cycle of 14 hours light and 10 hours dark. Fluorescent light lamps were used in the room housing rats to avoid the endogenous formation of vitamin " $D$ " by exposure to the ultraviolet rays of the sun light (Halloran and DeLuca, 1980).

Five days before sacrifice a vaginal smear was done daily at a fixed time of the day to detect the phase of estrous cycle. Rats of the control group were sacrificed during diestrus phase.

Both ovaries of each rat were dissected and examined for any gross changes. After fixation, the specimens were processed for paraffin embedding.

Serial sections 5-7 microns in thickness were prepared. The sections were divided into three groups. The first group was stained by Haematoxylin and Eosin to examine the various types of the ovarian follicles, corpora lutea and the ovarian medulla. Image analysis of those sections was carried out using the monitor's screen of the image analyzer, to count the various types of ovarian follicles and corpora lutea in each section by the interactive measure meau (Fig. 1). The second group was stained by Perl's Prussian blue for detection of the haemosiderin deposition in the ovary. In the third group Von Kossa method was used for detection of the calcium deposition.

\section{RESULTS}

\section{A-Effect on the estrous cycle:}

Vaginal smear examination of the control rats showed normal estrous cycle.

In the treated rats vaginal smear examination showed disturbed estrus cycle in the form of sustained diestrus phase in $80 \%$ of rats of subgroup A. All rats (100\%) of subgroup $B$ and $C$ exhibited a sustained diestrus phase.

Vaginal smear examination of the recovered rats showed various levels of improvement where all rats (100\%) of subgroup $A, 60 \%$ of rats of subgroup $B$ and only $30 \%$ of rats of subgroup $C$ regained their normal estrus cycle. The remaining rats of subgroup $B$ and $C$ sustained the diestrus phase. 


\section{B- Gross morphology of the ovary:}

The ovaries of rats of the control group were lobulated with clear grayish-pink coloration (Fig. 2-A).

In the treated group the ovaries appeared congested with reddishblack coloration. The congestion was moderate in subgroup $A$ (Fig. 2-B), marked in subgroup B (Fig. 2-C) and severe in subgroup C (Fig. 3-A).

In the recovered group residual congestion of the ovary was evident only in subgroup C (Fig. 3-B) but the other two subgroups simulate the control.

\section{C- Histological examination of the ovaries:}

\section{Control group:}

Histological examination of the ovaries revealed well demarcated peripheral cortex and central medulla. The cortex was covered by a single layer of germinal epithelium. Numerous ovarian follicles at various stages of development; primordial, primary, secondary and mature Graafian follicles were seen in the cortex close to the surface. Few atretic follicles were found among the developing follicles and the corpora lutea showed prominent vacuolations of their luteal cells. The medulla exhibited prominent vasculature within the loose connective tissue (Figs. 4, 5,6). The ovarian tissues exhibited clear acidophilic staining by Perl's Prussian and Von Kossa stains (Figs. 7- A, B).

\section{Treated group:}

\section{Treated subgroup A:}

The growing follicles and the corpora lutea were decreased in number and size, the granulosa cell layer was thin in the secondary and mature follicles, where as the atretic follicles were increased in number as compared with the control (Table 1; figs.8-A,B).

Foamy macrophages were seen within some follicles (Fig. 8-B). Corona radiata cells in some secondary follicles showed partial detachment with apoptotic changes in their nuclei (Fig. 9).

Some corpora lutea showed slight congestion of their vessels, where as others exhibited abnormally dilated lymph vessels among their cells (Figs. 10-A, B). The deposition of haemosiderin was obviously seen (Fig. 11 A). Fine traces of black calcium deposits were detected in the granulosa cells around the oocyte (Fig. 11-B). 


\section{Treated subgroup B:}

The number of ovarian follicles and corpora lutea was decreased especially the secondary and mature follicles as compared with subgroup $A$ and controls. The mature follicles exhibited thin degenerated granulosa cell layer. In addition, the atretic follicles were increased in number (Table 1;fig 12).

The granulosa cells and corona radiata cells of some secondary follicles exhibited apoptotic changes with fragmentation of their nuclei (Fig. $13)$.

The corpora lutea were reduced in size with congested blood vessels (Fig. 12). Some of them showed decrease of their cellular vacuolations (Fig. 14-A) and infiltration with fat cells (Fig. 14-B). Foamy macrophages enclosing haemosiderin were detected in some corpora lutea (Fig. 14-C). Many corpora exhibited large dilated lymph vessels encroaching upon their cells.(Fig. 15).

Haemosiderin and calcium deposits were detected within some growing and atretic follicles (Figs. 16-A, B).

\section{Treated subgroup C:}

The number of different follicles and corpora lutea was markedly decreased but that of the atretic follicles were markedly increased in number in comparison with controls; in addition, some growing follicles were ruptured (Table 1;fig.17). The granulosa cells of the mature Graafian follicles showed apoptotic fragmentation of their nuclei and some of these granulosa cells were engulfed by macrophages (Fig. 18- A). The oocytes of some mature Graafian follicles were distorted (Fig. 18- B).

The corpora lutea exhibited less vacuolations, some apoptotic changes in the luteal cells (Fig. 19-A) and huge dilated lymph vessels (Fig. $19-\mathrm{B}$ ). Congested blood vessels were found within some corpora lutea (Fig.20- A).

The medullary blood vessels were markedly dilated and congested (Fig. 20-A) with perivascular inflammatory cellular infiltration (Fig. 20- B). Large areas of haemosiderin (Figs. 21-A, B) and calcium deposition were detected within various follicles and in the stroma of the ovary (Figs. 22- A, B).

\section{Recovered Group:}

\section{Recovered Subgroup A:}

The number of the primary, secondary and mature follicles was lower than that of the control but was higher than the treated subgroup A. However, the number of the atretic follicles was higher than the control group and the treated subgroup $A$. The size and configuration of the growing folli- 
cles as well as its granulosa cell layer were nearly the same as in the control ovaries. The corpora lutea were normal in size but their number was lower than that of the control group and higher than the treated subgroup $A$. They exhibited vacuolated luteal cells. (Table 1; fig.23). The medullary blood vessels were slightly congested (Fig. 23).Few haemosiderin deposits were detected, mainly in some atretic follicles and in the ovarian stroma. Calcium deposits could not be detected in this subgroup.

\section{Recovered subgroup B:}

The number of the different follicles was lower than that of the control group but was slightly higher than that of the treated subgroup $B$. On the other hand the number of atretic follicles was higher than the control and the treated subgroup B (Table 1;fig.24).

Many secondary and mature follicles showed slightly distorted configuration with thin but apparently normal granulosa cell layer.

The corpora lutea were of normal size but their number was lower than the control and slightly higher than the treated subgroups B (Table 1;fig.24). They exhibited slightly congested blood vessels and their luteal cells were moderately vacuolated. The medullary blood vessels showed slight congestion (Fig. 24). Few amounts of haemosiderin (Fig. 25- A) and calcium deposits (Fig. 25-B) were detected in the stroma of the ovary and some atretic follicles.

\section{Recovered Subgroup C:}

The number of the various follicles was markedly decreased than that of the control group but was slightly increased than the treated subgroup C (Table 1; fig.26).

The secondary and mature follicles were small in size with distorted configuration compared with the recovered subgroup $B$, but with a higher incidence (Fig. 26). The number of the atretic follicles was markedly increased than the controls and the treated subgroup C (Table 2).

The number of the corpora lutea was decreased in number and size (Fig. 26). Also there were marked congestion of their blood vessels. with diminished vacuolation of the luteal cells (Fig. 27-A) The medullary blood vessels were dilated (Fig. 26). Big amounts of haemosiderin deposits (Fig. 27-B) and calcium deposits (Fig. 28) were detected in some atretic follicles. 


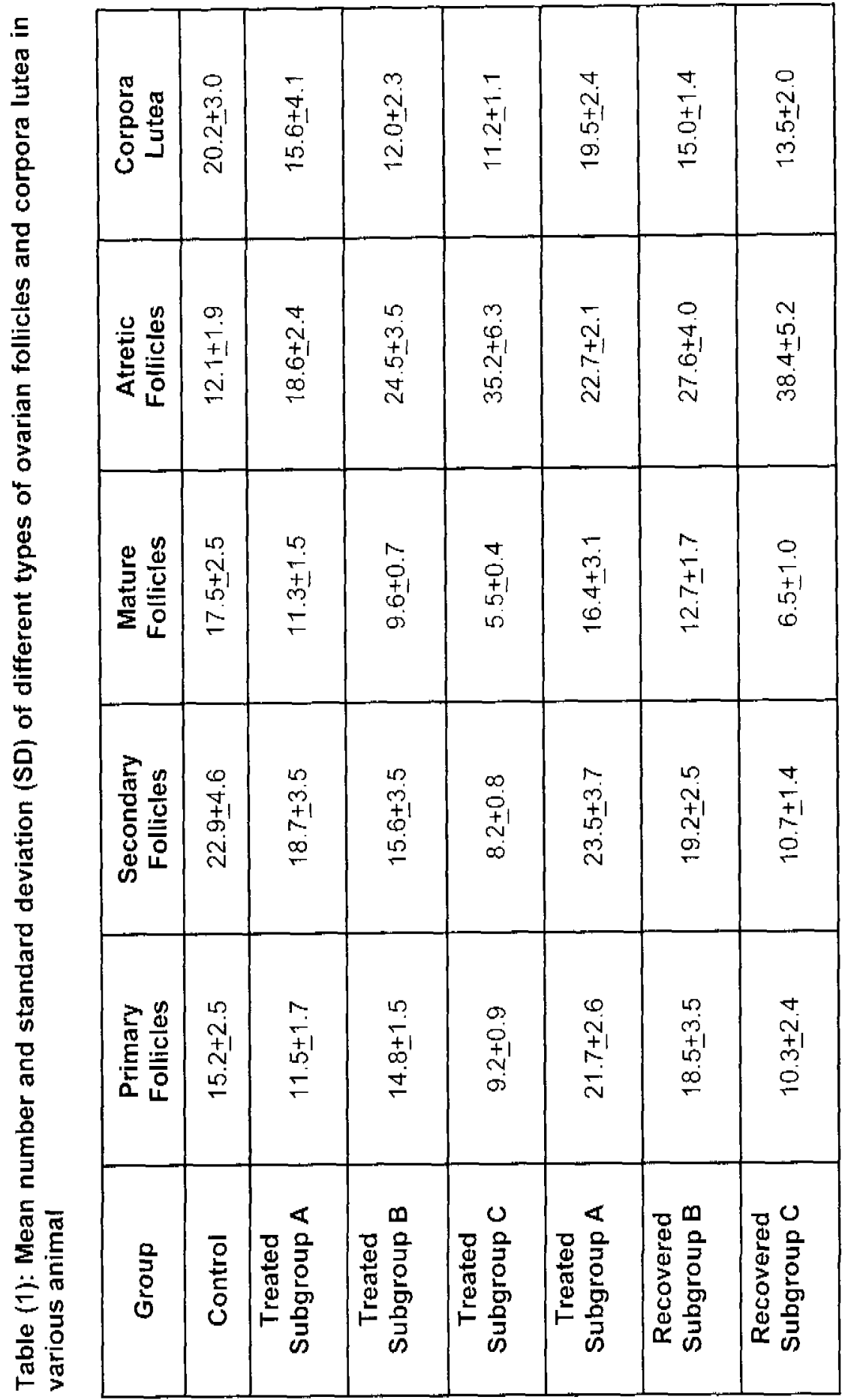




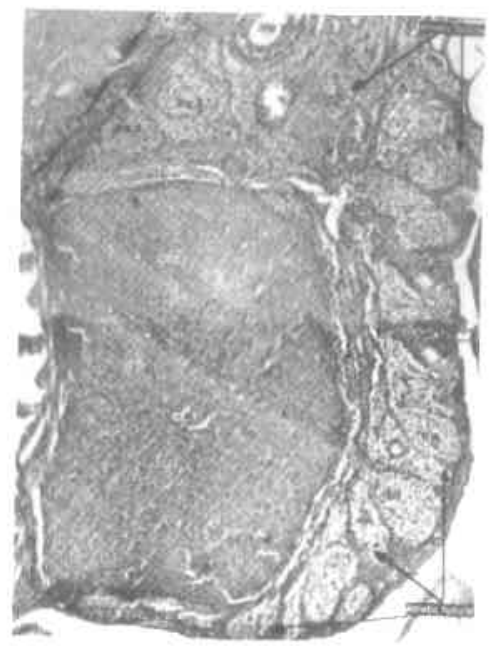

Fig. (1) :A photomicrograph of a display seen on the monitor' screen of the image analyzer showing the number of the follicles counted in one field of a section of an ovary from the control group. (Hx. \& E.; X 40)
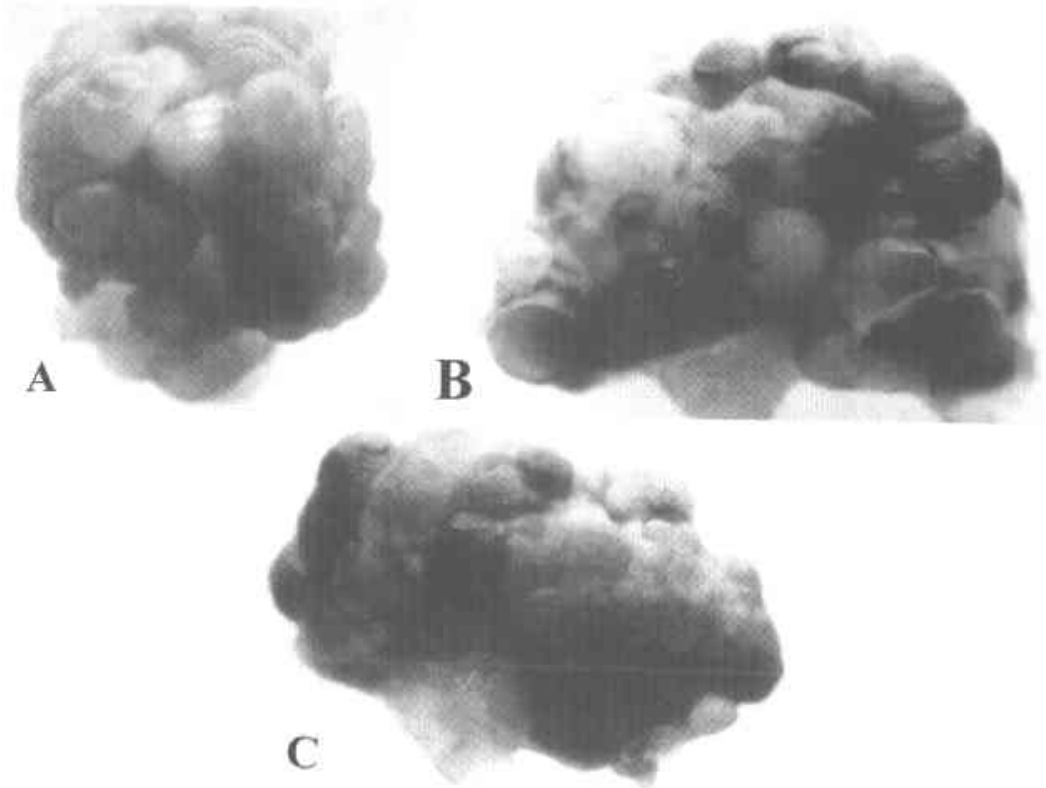

Fig. (2) :Photographs of three ovaries.

A: Ovary of a control rat with clear grayish-pink coloration.

$B$ : Ovary of a treated subgroup A rat which is moderately congested with reddish-black coloration.

C: Ovary of a treated subgroup B rat which is markedly congested. 

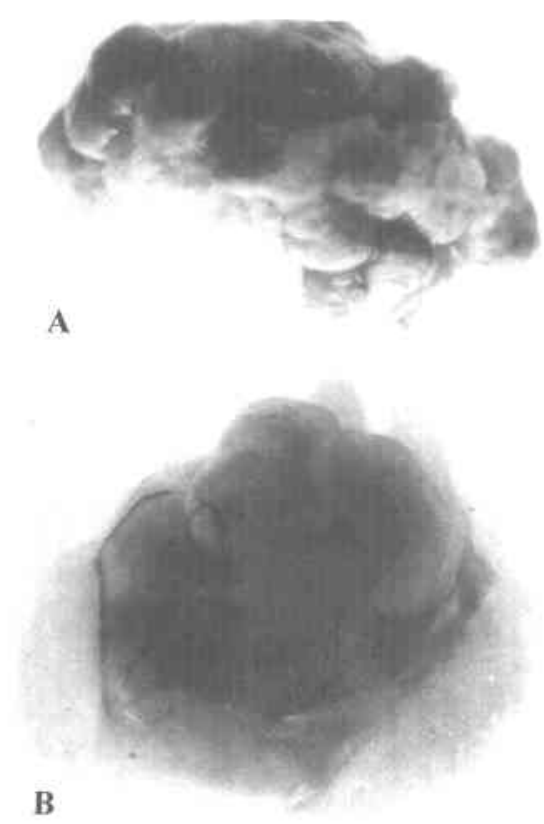

Fig. (3): Photographs of two ovaries.

A: Ovary of a treated subgroup $\mathrm{C}$ rat which is severely congested.

$\mathrm{B}$ : Ovary of a recovery subgroup $\mathrm{C}$ rat which shows residual congestion.

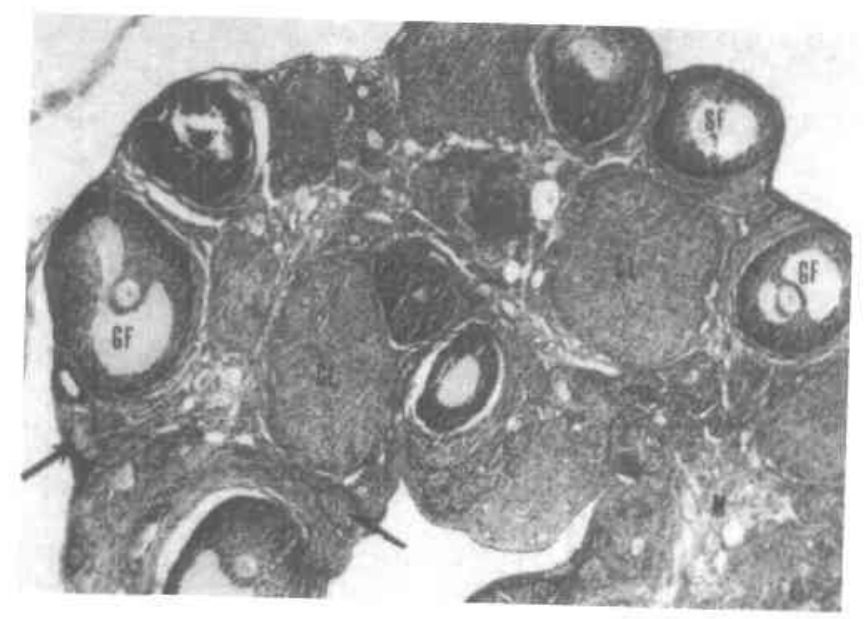

Fig. (4): A photomicrograph of a section of an ovary from the control group showing the cortex containing many mature Graafian follicles (GF), secondary follicles (SF), corpora lutea (CL) and few atretic follicles (arrows). The medulla $(\mathrm{M})$ is formed of loose vascular connective tissue.

(Hx, \& E.; X 25) 


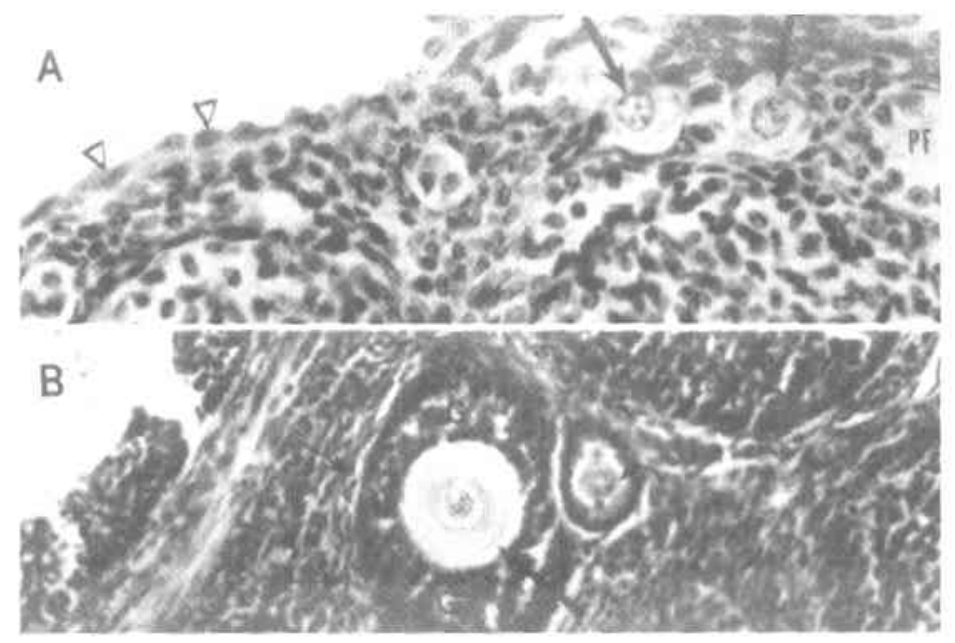

Fig. (5):Photomicrographs of sections from two ovaries of the control group.

A: Section showing the germinal epithelium (arrow heads) and many primordial follicles (arrows).(Hx.\& E.; X 400)

$B: S e c t i o n$ showing a multilaminar primary follicle (thick arrow), stratified granulosa cells (G) and theca layer (thin arrow).(Hx.\& E.; X 400)
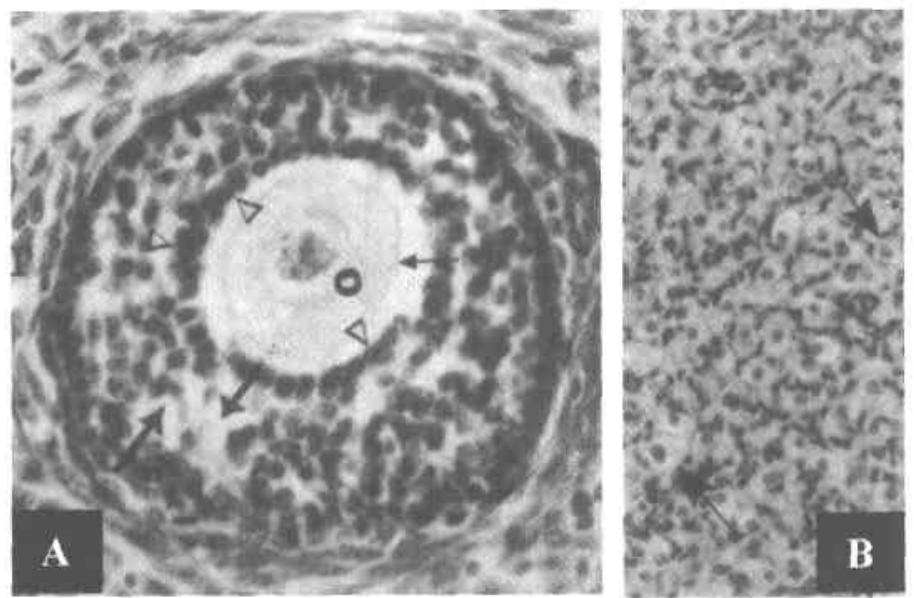

Fig. (6): Photomicrographs of sections from two ovaries of the control group.

A: Section showing a secondary follicle with small antral cavities (thick arrows), prominent theca folliculi layer $(T)$, corona radiata (arrow heads), zona pellucida (thin arrow) and oocyte (O). (Hx. \& E; X 400) $\mathrm{B}$ :Section showing vacuolated luteal cells (arrows) in corpus luteum.

(Hx. \& $E . ; \times 400$ ) 

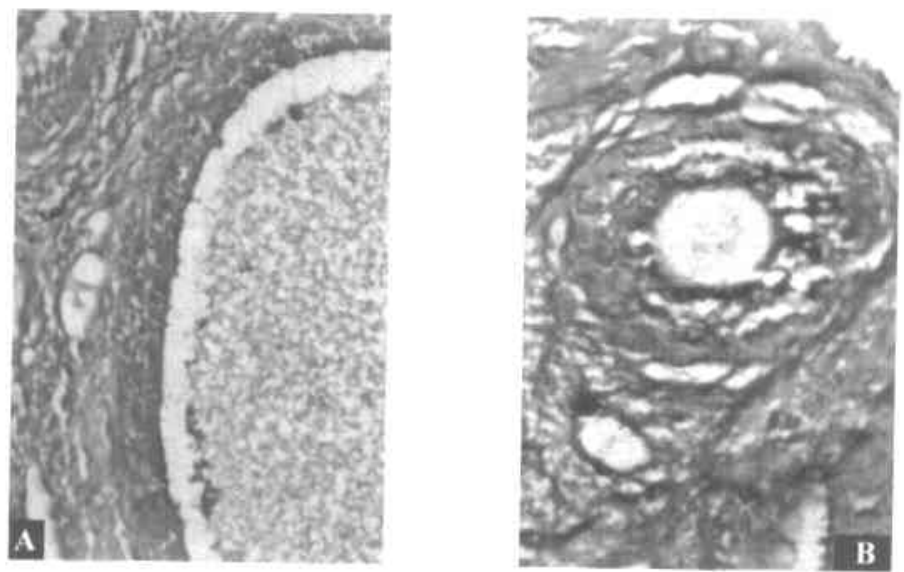

Fig. (7):Photomicrographs of sections from two ovaries of the control group.

A:Section showing acidophilic staining of the ovarian tissue by Perls Prussion stain (Perls Prussion stain; X 200).

B:Section showing acidophilic staining of the ovarian tissue by Von Kossa stain (Von Kossa stain; X 200).
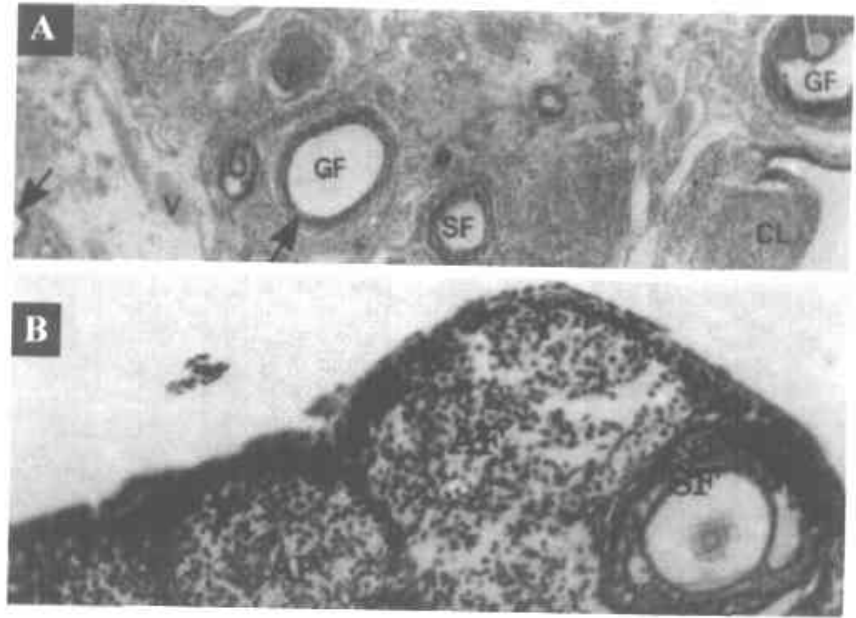

Fig. (8): Photomicrographs of sections from two ovaries of rats from the treated subgroup A.

A: Section showing few small sized mature Graafian follicles (GF), secondary follicles (SF), corpora lutea (CL). Congested medullary vessels $(\mathrm{V})$ and thin granulosa cell layer of the secondary and mature follicles (arrows). $(H x, E . ; X 40)$

B: Section showing atretic follicles(AF) and a foamy macrophage(arrow) within granulosa cells of a secondary follicle (SF) .(HX, E.; X 200) 


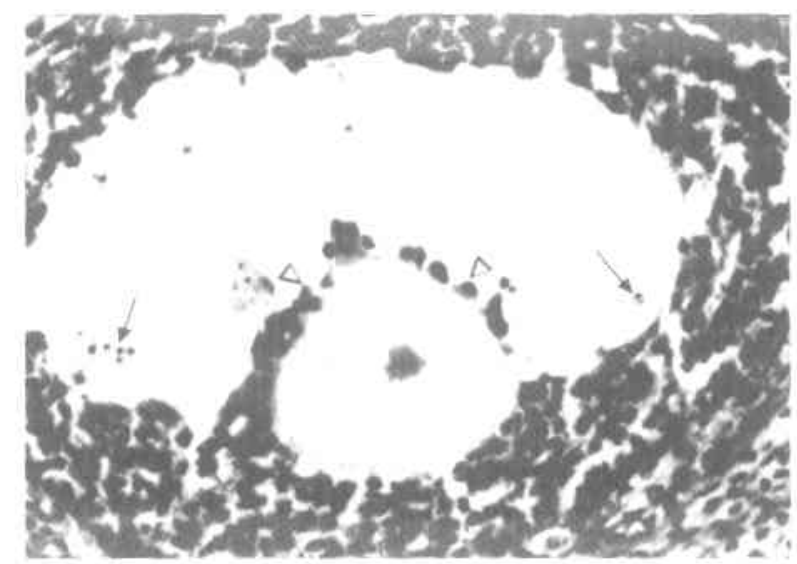

Fig. (9): A photomicrograph of section of a rat ovary from the treated subgroup A showing a secondary follicle approaching maturity. The oocyte is seen surrounded by few corona radiata cells (arrow heads). Some of the corona cells are seen detached inside the antral cavity with apoptotic nuclei (arrows).(Hx. \& E.; X 400)
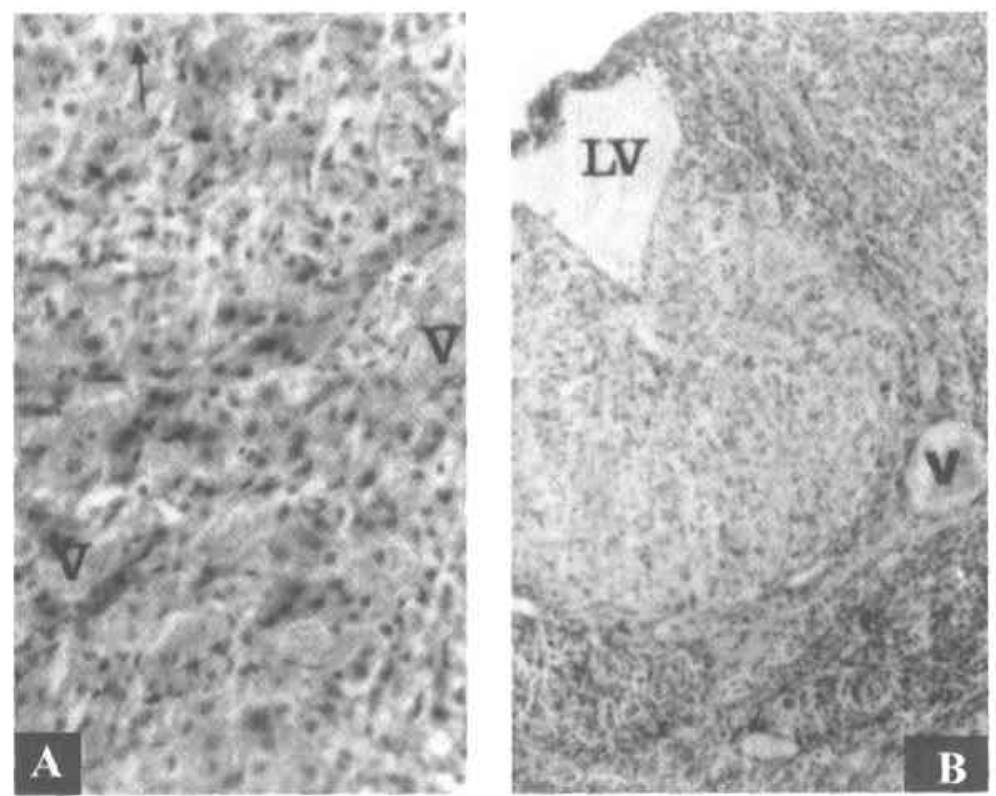

Fig. (10): Photomicrographs of sections from two rat ovaries from the treated subgroup A.

A:Section showing congested blood vessels $(V)$ in corpus luteum with vacuolated luteal cells (arrow). (Hx. \& E.; X 200)

$B:$ Section showing a large dilated lymph vessel (LV) within corpus luteum and a congested blood vessel (V).. (HX. \& E.; X 100) 


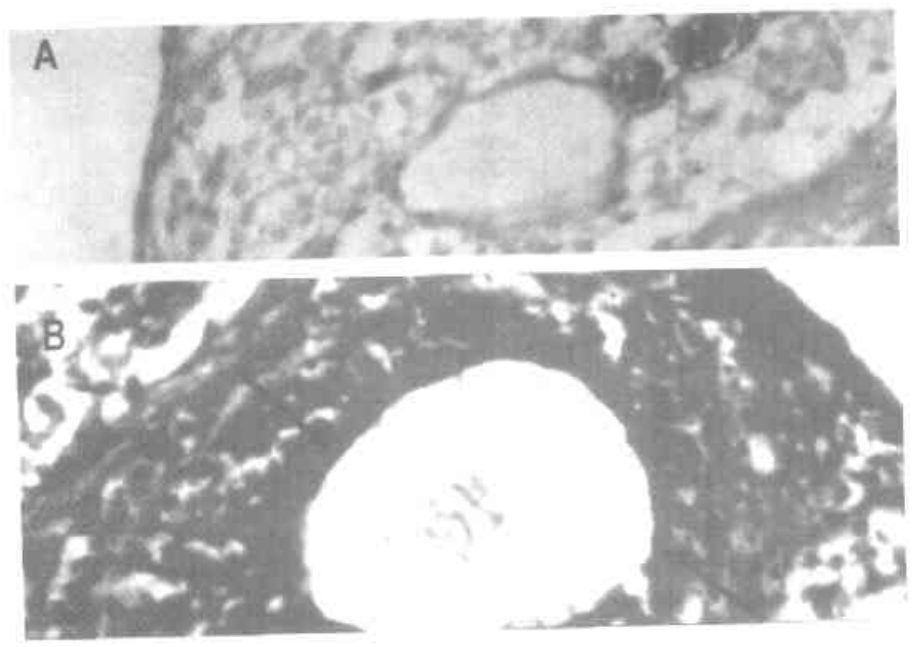

Fig. (11): Photomicrographs of sections from two rat ovaries from the treated subgroup $A$ :

A: Section showing basophilic staining of haemosiderin deposits (arrow) in an atretic follicle.(Perl's Prussian stain; $X 400$ )

$B$ : Section showing fine traces of black calcium deposits (arrows) in the innermost granulosa cell layer of a growing follicle.

(Von Kossa srain;X 400)

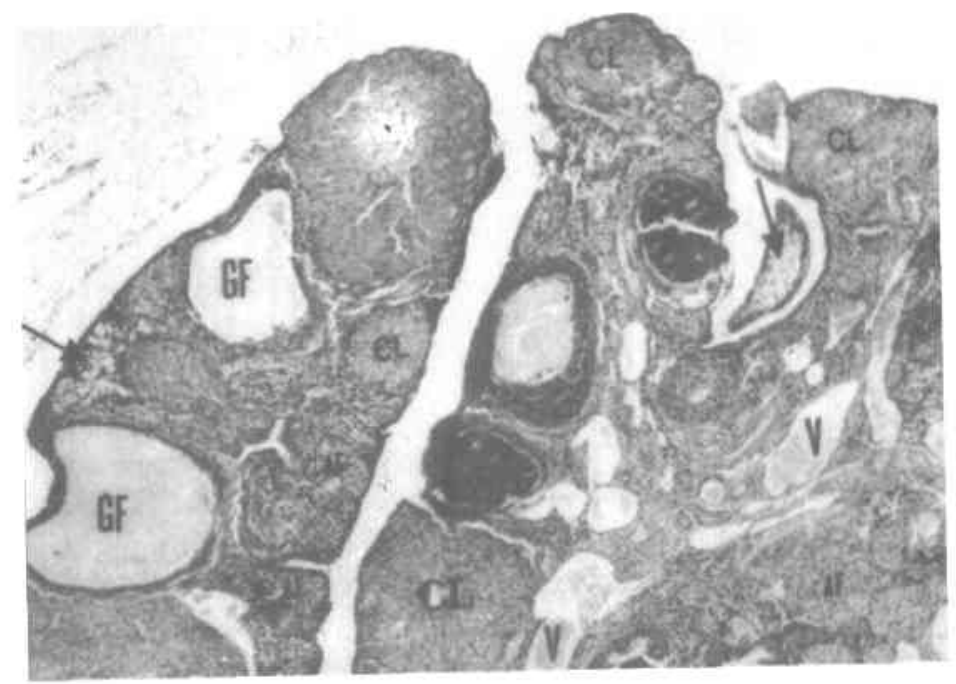

Fig. (12): A photomicrograph of a section of rat ovary from the treated subgroup B showing markedly deformed mature Graafian follicles (GF) with thin granulosa cell layer, small sized corpora lutea (CL) and markedly dilated and congested medullary vessels (V). Many atretic follicles (AF) with areas of haemosiderin deposits (arrows) are also seen. (Hx. \& E.; X 40) 


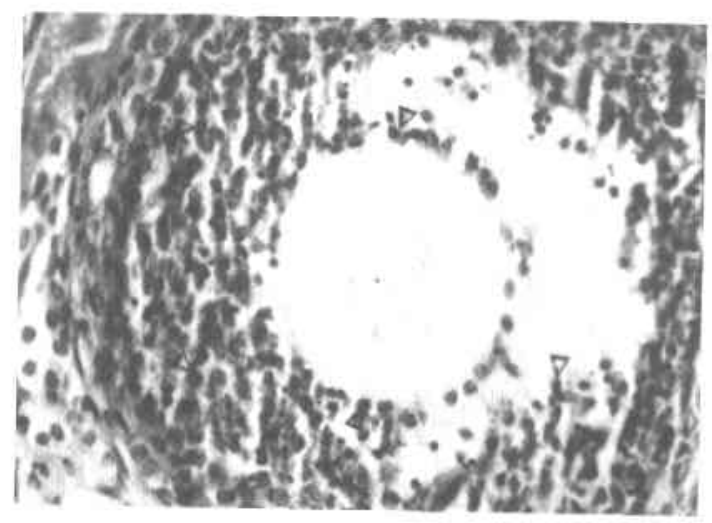

Fig. (13): A photomicrograph of a section of rat ovary from the treated subgroup B showing a large secondary follicle with few corona radiata cells irregularly surrounding the oocyte. Some of the granulosa and corona cells exhibit apoptosis (arrow heads). ( $\mathrm{Hx}$ \& \& E.; X 400)
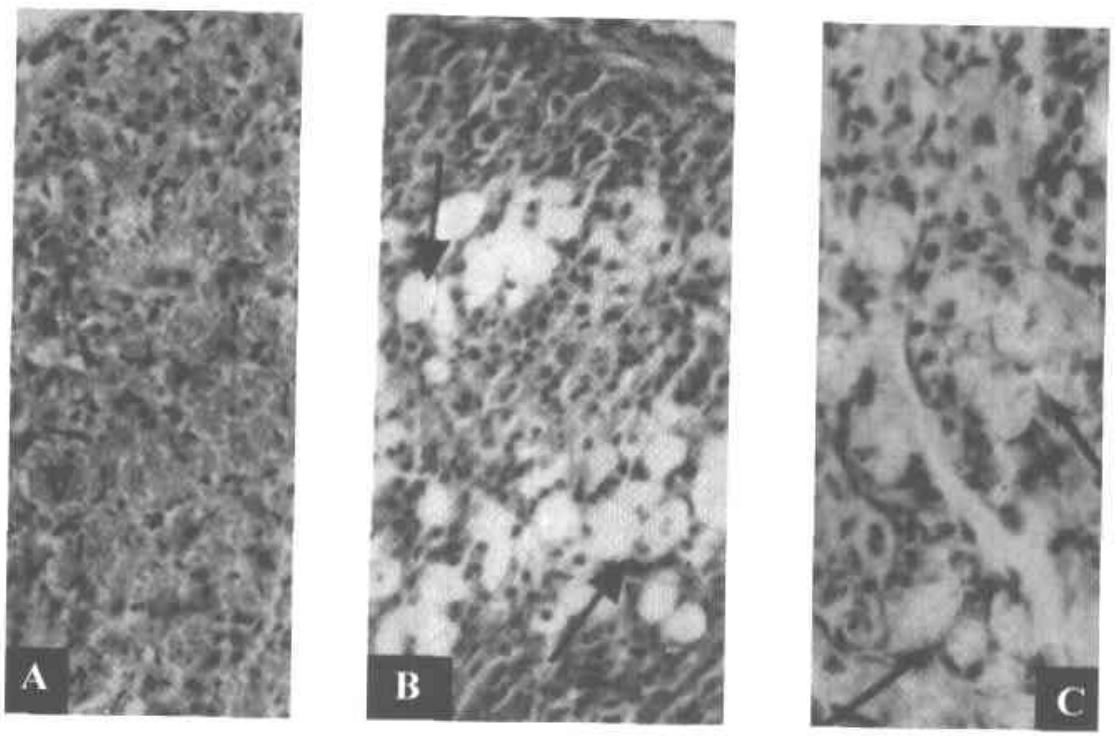

Fig. (14): Photomicrograps of sections of three rat ovaries from the treated subgroup $B$.

A: Section showing a part of a corpus luteum with diminished vacuolation of its cells with numerous congested blood vessels (V). (HX. \& E.; X 200)

$B$ : Section showing a part of a corpus luteum infiltrated with large number of fat cells (arrows). (Hx. \& E.; X 200)

C: Section showing a part of a corpus luteum with haemosiderin pigments phagocytosed by foamy macrophages (arrows). (Hx.\& E.; X 400) 


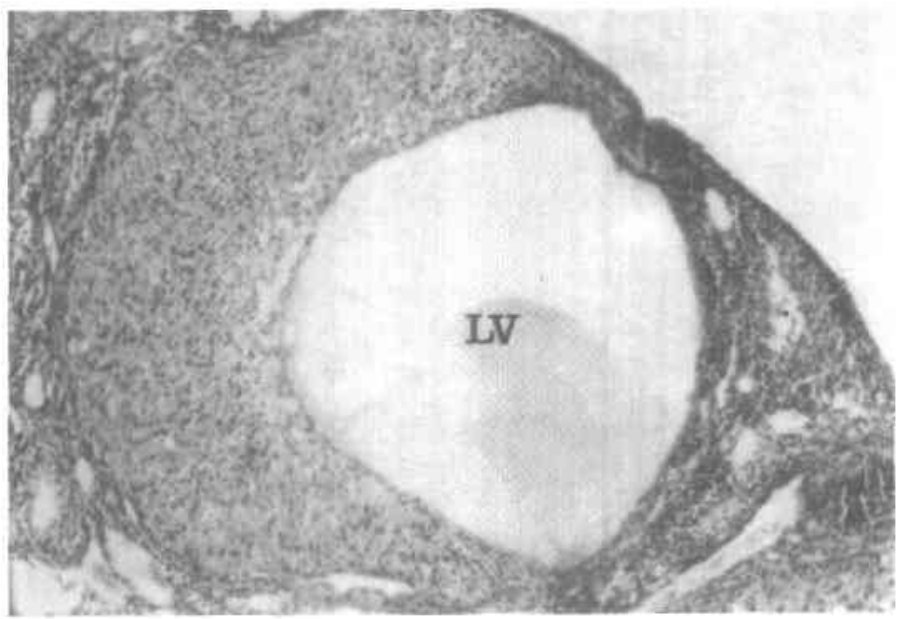

Fig. (15): A photomicrograph of a section of a rat ovary from treated subgroup B showing markedly dilated lymph vessel (LV) encroaching upon the cells of a corpus luteum. (Hx. \& E.; X 100)
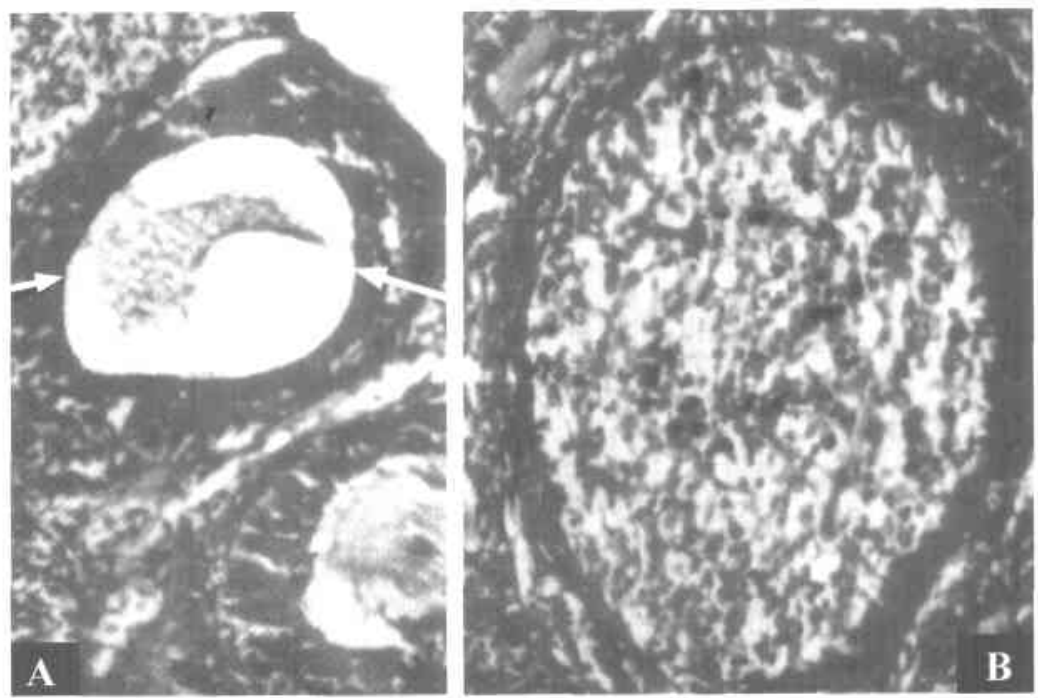

Fig. (16): Photomicrographs of sections of two rat ovaries from the treated subgroup B.

A: Section showing a very thin black line of calcium deposition in the innermost granulosa cell layer (arrows) of a secondary follicle and in the germinal epithelium (arrow heads). (Von Kossa stain ; $X$ 400)

$B$ : Section showing heavy calcium deposition in an atretic follicle.

(Von Kossa stain; $X 400$ ) 


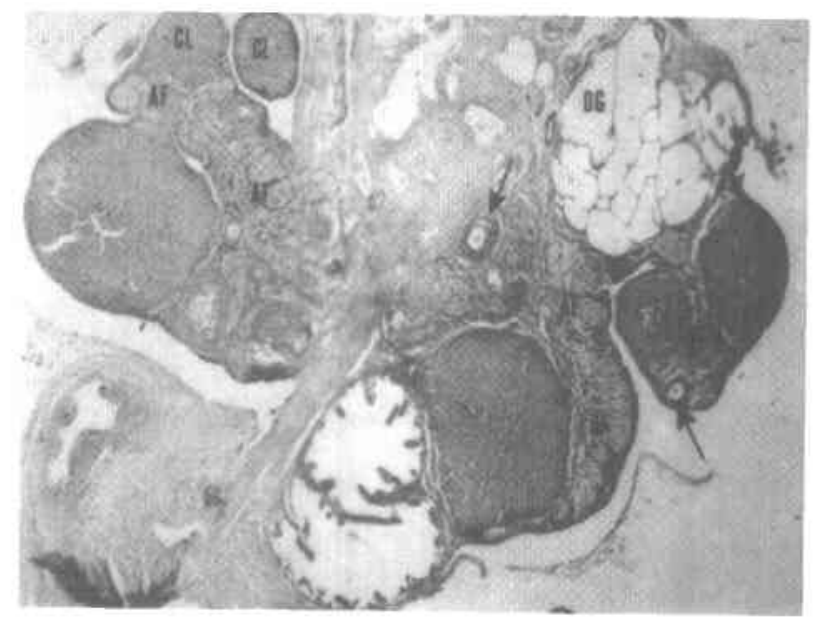

Fig. (17): A photomicrograph of a section of a rat ovary from the treated subgroup $C$ showing mature Graafian follicles with thin granulosa cell layer (arrows) and many atretic follicles (AF). Some corpora lutea $(\mathrm{CL})$ are of small size. Note the degenerated ruptured growing follicle (DG). (Hx. \& E.; X25)
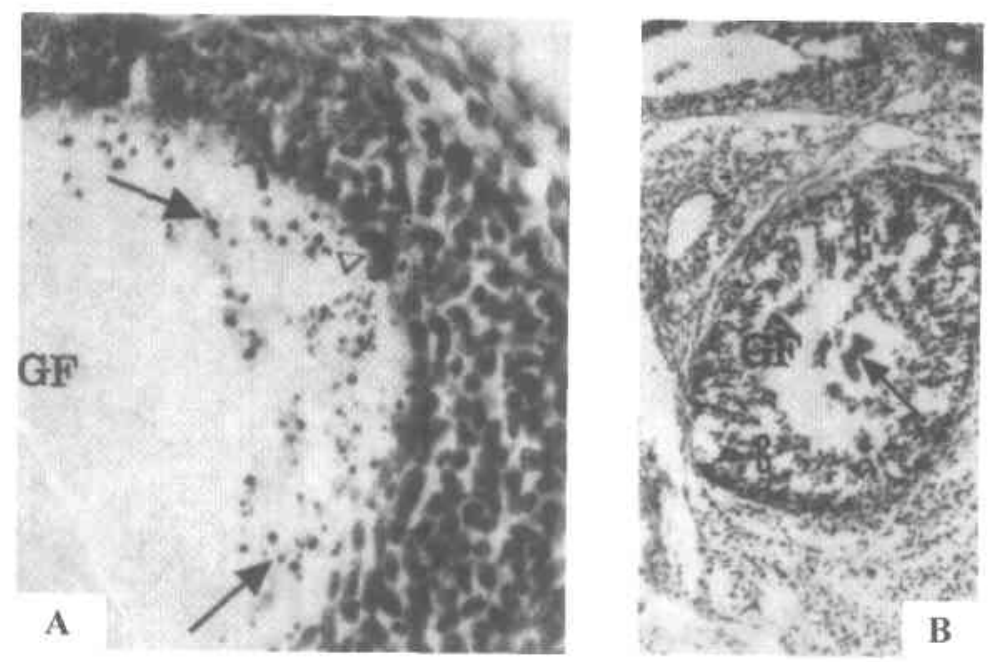

Fig. (18): Photomicrographs of sections of two rat ovaries from the treated subgroup C.

A:Section showing apoptotic granulosa cells (arrows) detached inside the antral cavity of mature Graafian follicle (GF) and some of them are engulfed by macrophages (arrow head). (Hx.\& E.; X 400)

$B: S e c t i o n$ showing degeneration and wide separation of the granulosa cells (G) in a mature Graafian follicle (GF) and degenerated oocyte (arrow). (Hx. \& E.; X 200) 


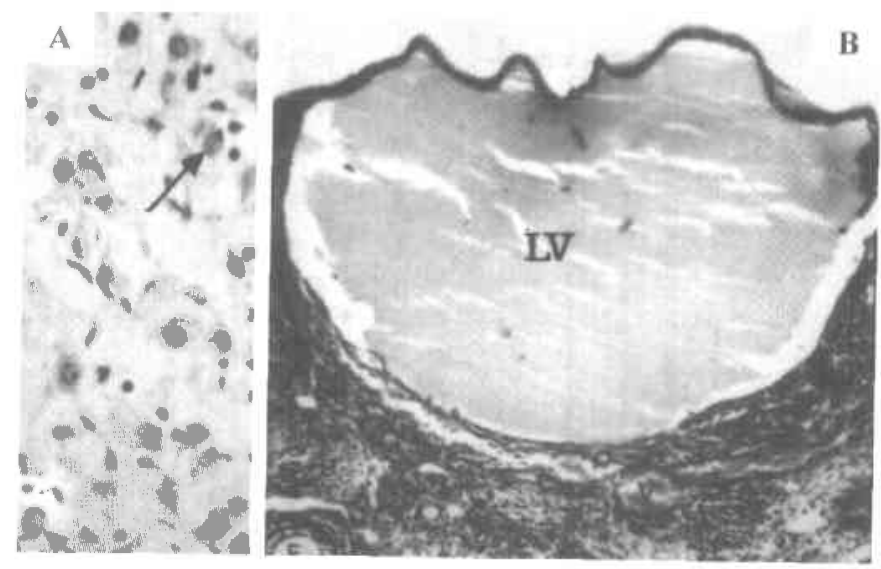

Fig. (19): Photomicrographs of sections of two rat ovaries from the treated subgroup C.

A: Showing apoptotic cells (arrows) among the corpus luteum, the cells are widely separated by intercellular spaces with diminished vacuolation. (HX. \& E. ; X 400)

$B$ : Showing huge dilated lymph vessel (LV) encroaching on most of cells of a corpus luteum, a growing follicle $(F)$ and congested medullary vessels $(V)$. (Hx. \& E.; X 100)
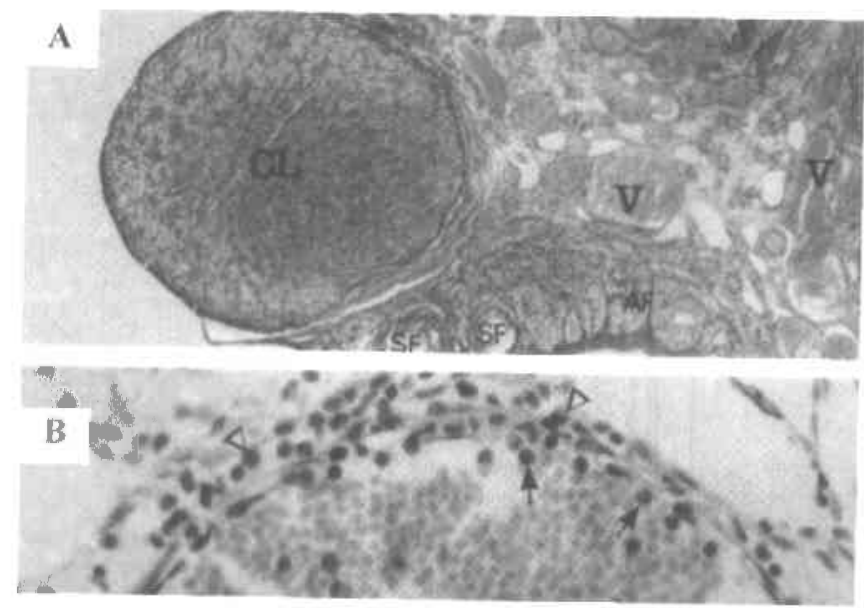

Fig. (20): Photomicrographs of sections of two rat ovaries from the treated subgroup $\mathrm{C}$.

A: Section showing a congested corpus luteum $(\mathrm{CL})$ and medullary blood vessels (V). Also an atretic follicle (AF) and small secondary follicles (SF). (HX. \& E. ; X 40)

B: Section showing different types of inflammatory cells (arrows) marginating the inner wall of a blood vessel and some of them are seen outside the vessels (arrow heads). (Hx. \& E.; X 400) 

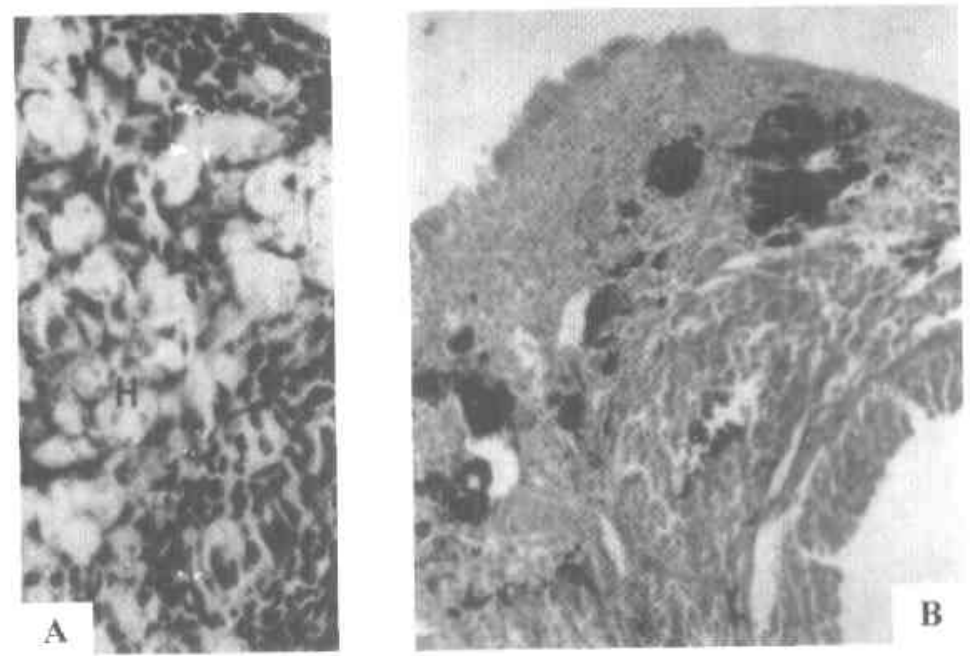

Fig. (21): Photomicrographs of sections of two rat ovaries from the treated subgroup $\mathrm{C}$.

A: Section showing haemosiderin pigments in the stroma of the ovary (H). (HX. \& E.; X 400)

$B$ : Section showing basophilic staining of the haemosiderin pigments deposited in the ovarian cortex. (Perl's Prussian stain; X 200)
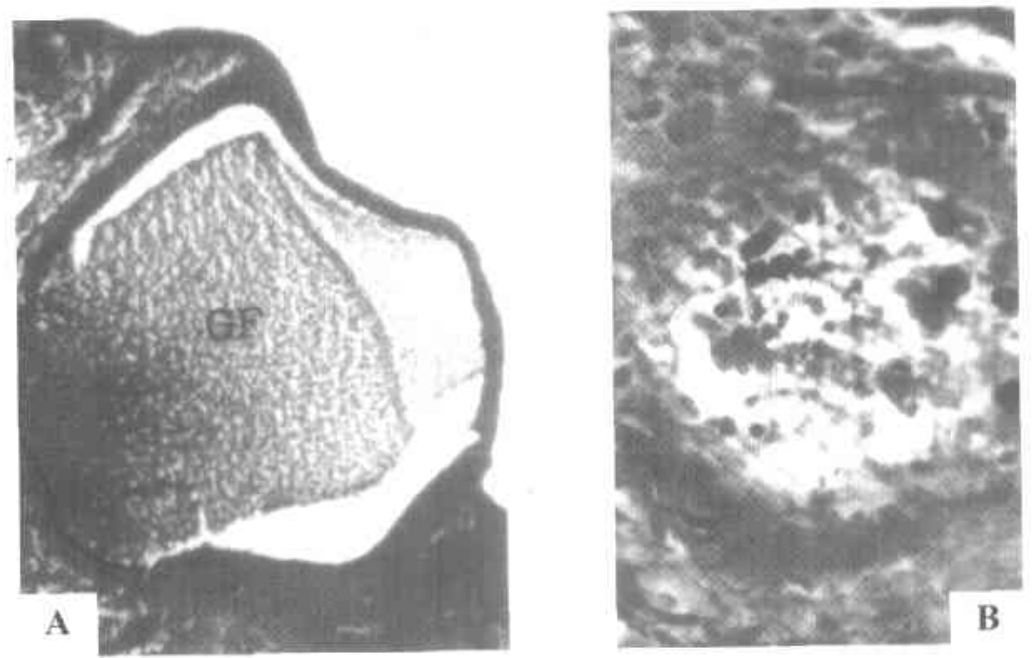

Fig. (22): Photomicrographs of sections of two rat ovaries from the treated subgroup $\mathrm{C}$.

A: Section showing linear calcium deposition in wall of a disfigured mature Graafian follicle (GF). (Von Kossa; X 100)

$\mathrm{B}$ : Section showing numerous scattered calcium deposits in an atretic follicles. (Von Kossa; X 400) 


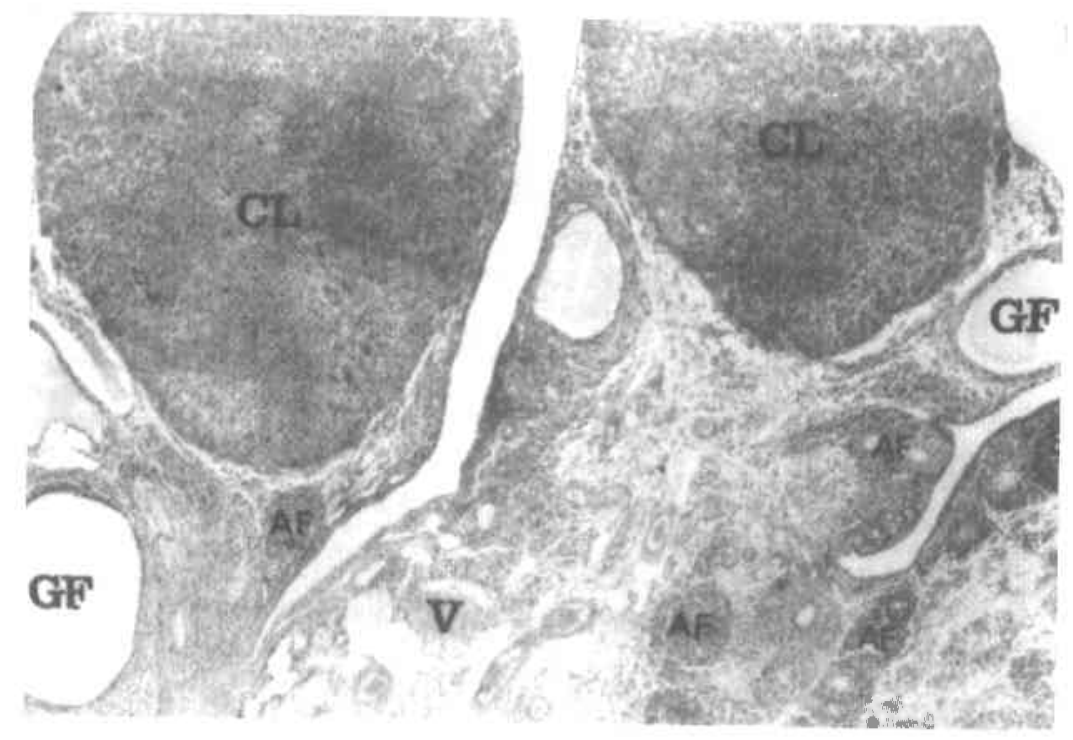

Fig. (23): A photomicrograph of a section of rat ovary from the recovered subgroup A showing atretic follicles (AF), Graafian follicles (GF) and corpus luteum (CL) and a dilated blood vessel (V). (Hx. \& E.; X 40)

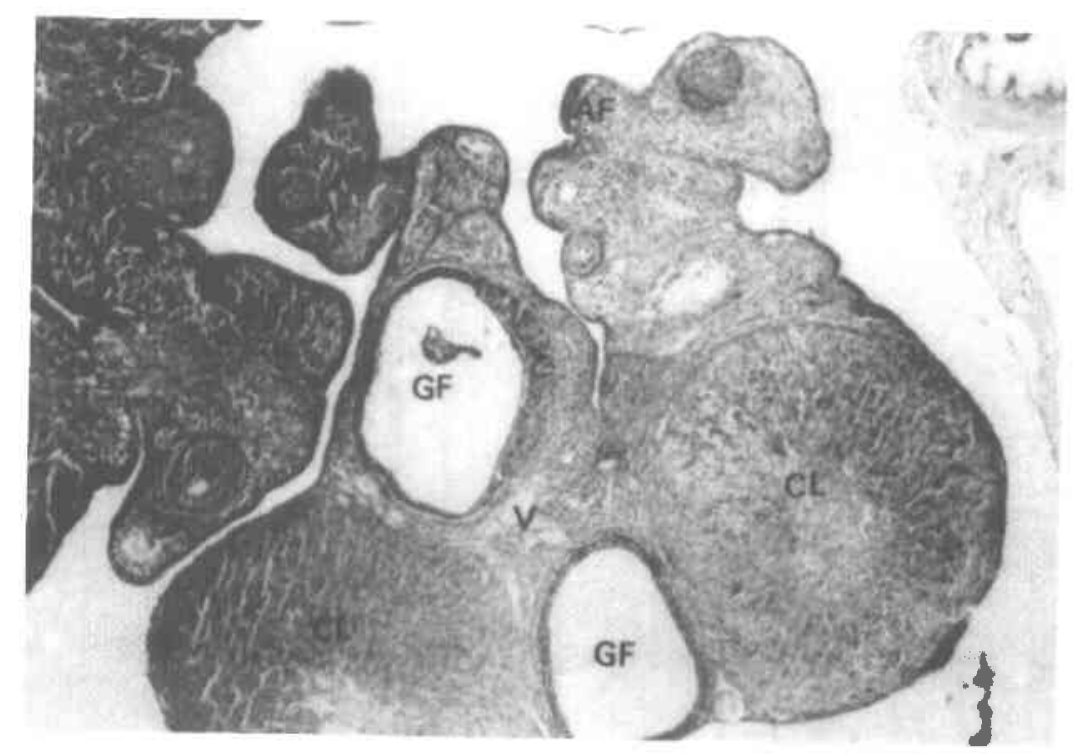

Fig. (24): A photomicrograph of a section of rat ovary from the recovered subgroup B demonstrating slightly distorted mature Graafian follicles (GF) with thin granulosa wall, copora lutea $(\mathrm{CL})$ and some atretic follicle (AF). A medullary blood vessel (V) shows slight congestion. (Hx. \& E.; X 40) 

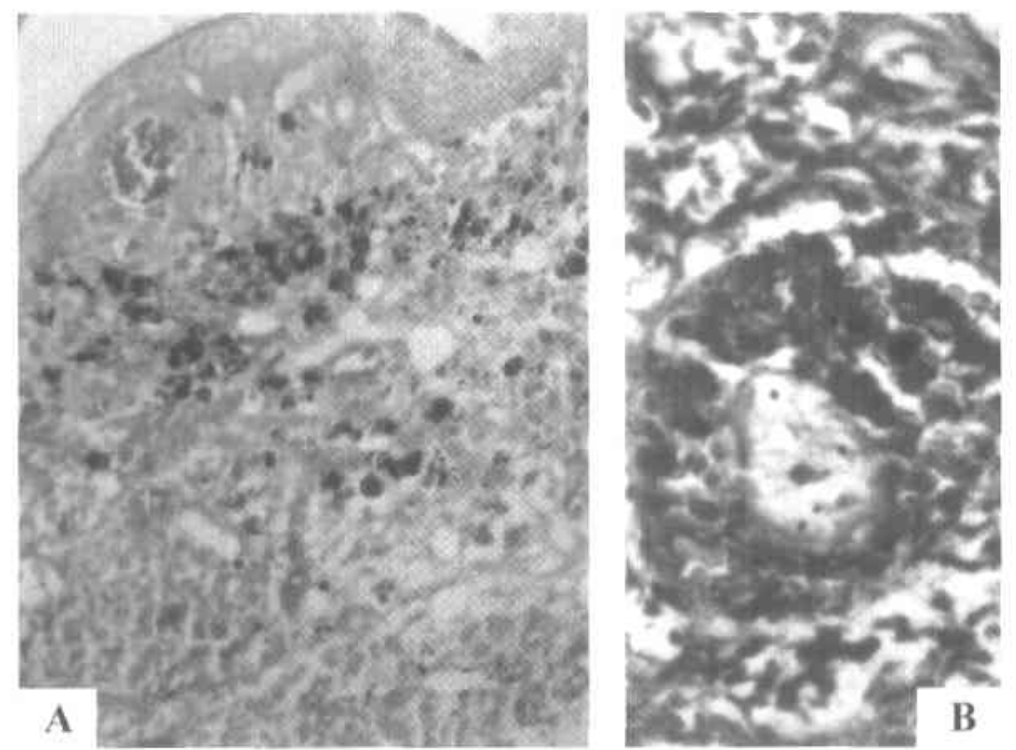

Fig. (25): Photomicrographs of sections of two rat ovaries from the recovered subgroup B.

A: Section showing moderate haemosiderin deposits in the stroma of the ovary. (Perl's Prussian stain; $X 200$ )

$B$ : Section showing few calcium deposits in an atretic follicle. (Von Kossa stain; $X$ 400)

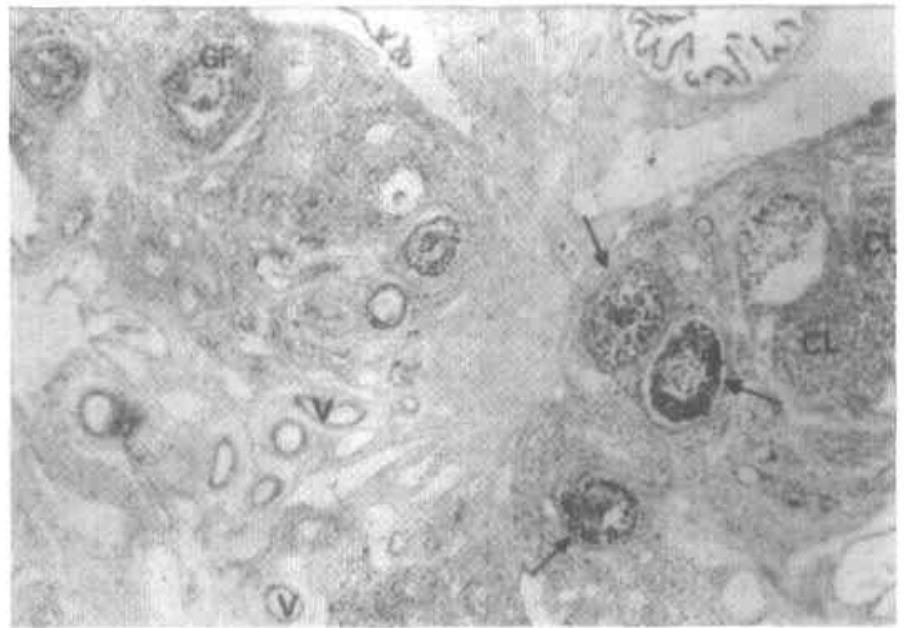

Fig. (26): A photomicrograph of a section of rat ovary from the recovered subgroup $\mathrm{C}$ showing small-sized mature Graafian follicle (GF) and multiple distorted secondary follicles (arrows). Small-sized corpora lutea (CL) and dilated medullary vessels (V) are also seen. (HX. \& E.; X 40) 

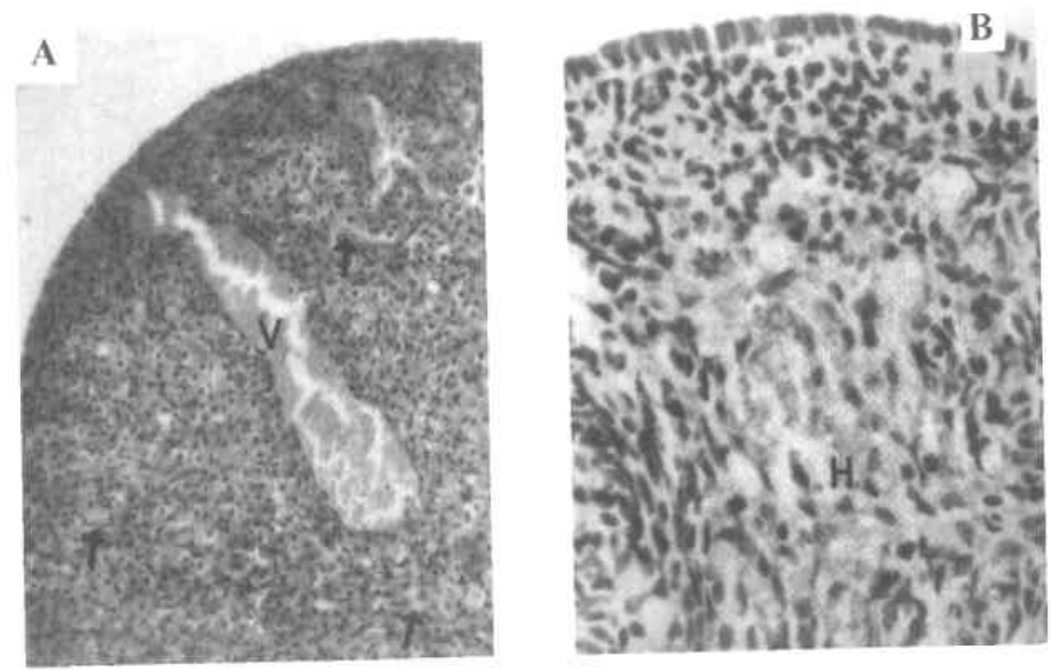

Fig. (27): Photomicrographs of sections of two rat ovaries from the recovered subgroup $C$.

A: Section showing a corpus luteum containing markedly congested blood vessels $(V)$ and slight vacuolation of its luteal cells (arrows). (Hx. \& E.; X 100)

$B$ : Section showing haemosiderin pigments within an atretic follicle $(H)$. (Hx. \& E.; A X 400)

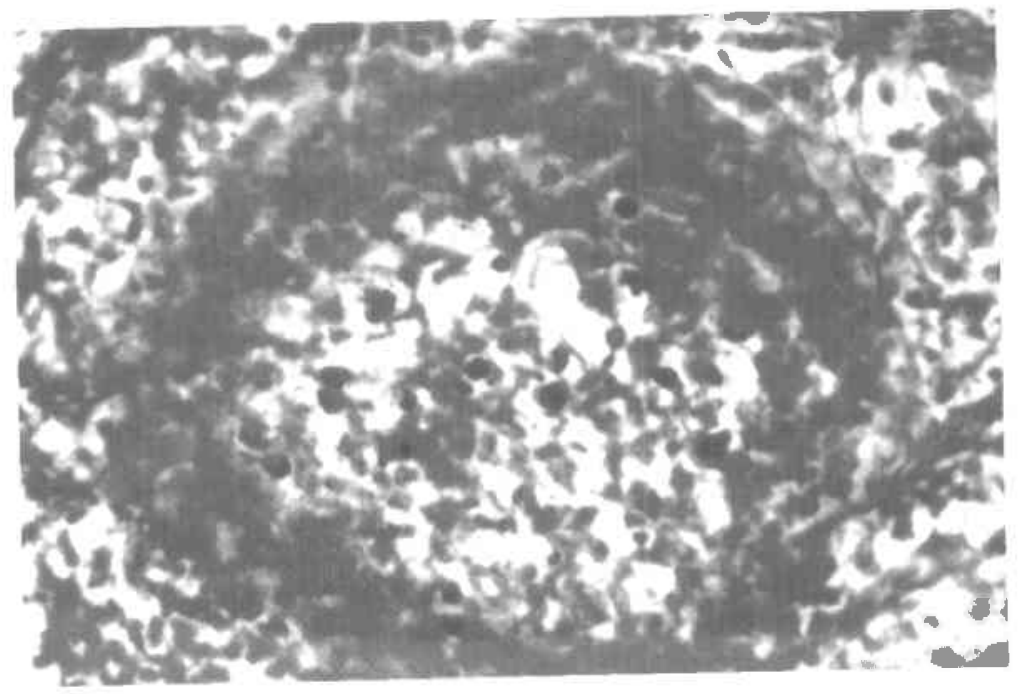

Fig. (28): A photomicrograph of a section of rat ovary from the recovered subgroup $C$ showing calcium deposits in an atretic follicle. (Von kossa stain; X 400) 


\section{DISCUSSION}

The effect of hypervitaminosis " $D$ " on the ovary of the albino rat was investigated in the present work using three different levels of hypervitaminosis. The current study showed that the effect of the hypervitaminosis " $D$ " on the estrous cycle was in the form of sustained diestrus phase in the treated group. These results are in agreement with the previous findings of Horii et al. (1992) who detected sustained diestrus phase in the rats which received high doses of vitamin "D". These authors correlated this to the disfunction of the corpora lutea. In the recovered group when the rats were left to live four weeks after the last dose the effect was reversed in 100\%,60\% and $30 \%$ of the rats of subgroups A, B and C respectively, i.e.they could regain their normal estrous cycle.

In the treated group of the present work histological examination of the ovaries showed that the number of the growing and the mature follicles was decreased. However, the number of the atretic follicles was increased in comparison with the control. As the reduction of the number of the secondary and mature follicles was more than the reduction of the number of the primary follicles, hypervitaminosis " $\mathrm{D}$ " can be considered as a suppressive agent for the maturation of the follicles but not as an inhibitory factor for the beginning of the ovarian cycle. The above finding is in agreement with the finding of Horii et al. (1992) who declared that the hypervitaminosis "D" had adversely affected the follicular maturation which consequently suppressed the ovulation and the formation of the corpora lutea. On the other hand, the presence of the corpora lutea should not be regarded as a sign of a successful complete follicular cycle ending by the ovulation in the treated group as these corpora may be formed in the previous cycles before the exposure to hypervitaminosis " $\mathrm{D}$ ". This latter observation is supported by the report of Freeman (1988) who said that when the female albino rat stopped cycling, the corpora lutea formed during the previous cycles would not regress rapidly and can be found in the ovaries.

In this study the number of all growing follicles and corpora lutea was restored after four weeks in all recovered subgroups; being marked in the subgroup $A$, moderate in the subgroup $B$ and minimal in the subgroup $C$. These results are in agreement with the observations of Dokoh et al. (1983) who reported that the physiological level of the vitamin " $D$ " could not inhibit the growth of the Chinese hamster ovarian cells in the culture medium but the vitamin overdose can do it.

In the present work, the examination of the structure of the secondary and the mature follicles in the treated group showed mild reduction in thickness of the granulosa cell layer in subgroup $A$ and marked reduction associated with degenerative changes in the form of the fragmentation and the presence of wide space between the cells in subgroup $B$. These 
changes were marked in subgroup $\mathrm{C}$ with rupture of some degenerated follicles. Nebel and Ornstein (1966) observed irregular granulosa cell layer in the few mature follicles in albino rats in cases of hypervitaminosis " $\mathrm{D}$ ".

The nuclei of the different follicular cells in the present work showed apoptotic changes in the form of fragmentation, in the treated group with appearance of the macrophages among the cells. These changes were restricted only to the corona radiata cells of the secondary follicles in subgroup $A$, but in subgroups $B$ and $C$ they affected all the granulosa cell layers. Woolf (2000) found that the apoptosis was usually inconspicuous, being short in duration and associated with the appearance of the macrophages which engulfed these apoptotic cells. He further reported that the appearance of the apoptotic cells even in a small proportion indicated the occurrence of major cell damage.

The recovered subgroups $A$ and $B$ showed improvement in the general architecture of the ovarian follicles. On the other hand, the follicles in the recovered subgroup $\mathrm{C}$ showed distortion in their configuration. In accordance with the present work, Horii et al. (1992) detected normal ovarian follicles in the rats after three weeks recovery from receiving high doses of vitamin "D".

The present investigation showed that the corpora lutea were not only infiltrated with fat cells but also showed diminished vacuolations of their luteal cells in all treated subgroups. Victor (1993) postulated that the cells of the corpus luteum normally acquire vacuolated lightly stained cytoplasm with the onset of its steroid secretory activity. Thus, the reduction of these vacuolations in our work is an indication of diminished hormonal secretory function of the corpora lutea with subsequent drop in the level of serum level of estrogen and progesterone. This hormonal disturbance might explain the disturbance of the estrous cycle in the form of sustained diestrous phase in the rats of the treated group and the recovered subgroup C. However, Johnson et al. (1996) reported that the malfunction of corpus luteum in the cases of hypervitaminosis " $\mathrm{D}$ " is based on the detection of intense staining of the luteal cells for VDRs (Vitamin D receptors).

In the recovered group of this work, the vacuolation of the luteal cells was restored to the control level in subgroup $A$, and slightly diminished in subgroup $B$ but was still minimal in subgroup $C$. However, Horii et al. (1992) detected that the corpora lutea of all rats regained their normal vacuolations after two weeks recovery from hypervitaminosis " $\mathrm{D}$ " whatever the level of the given doses.

This study proved the inflammatory effect of vitamin " $\mathrm{D}$ ". As the dose of vitamin "D" administrated to the treated subgroup $C$ was increased, the congestion of the medullary blood vessels and the inflammatory cells in the congested vessels increased. This congestion of the medullary blood vessels was reflected on the external morphology of the ovaries of the treated 
group which appeared reddish-black in color. These findings are controversial with the findings of Nebel and Ornstein (1966) who did not find any morphological changes in the ovaries of the rats which received high doses of vitamin " $\mathrm{D}$ ". In the present study, marked improvement of the inflammatory reaction and the morphology of the ovaries occurred in the recovered subgroups $A$ and $B$ but not in the recovered subgroup $C$.

Anderson (1976) stated that hypervitaminosis " $D$ " can be considered as a chemical agent which makes transient constriction of the arterioles followed by wide dilatation of both arterioles and venules, and proteinrich fluid escapes from the blood vessels into the extravascular tissues producing inflammatory edema that is drained by the lymph vessels which become dilated. These observations of the latter author can explaine the dilatation of lymph vessels in the corpora lutea in this work

The detected congestion in the ovaries of the treated and the recovered subgroup $\mathrm{C}$ could explain the occurrence of the haemosiderosis which was detected in many ovarian structures of the treated group and the recovered subgroup C. These agreed with Anderson and Kissane (1977) who stated that haemosiderosis occurred around areas of bruising and haemorrhage and in organs subjected to the congestion.

In this investigation, calcium deposits were found in the granulosa cell layer of the growing follicles in all treated subgroups. The intensity of calcium deposits was augmented in the treated subgroups B and C in which also calcium deposits were detected in some atretic follicles. In agreement with the present work, Woolf (2000) detected calcium deposits in the granulosa cells of the secondary follicles following hypervitaminosis " $\mathrm{D}$ ". Anderson and Kissane (1977) and Morita et al. (1995) correlated the calcium deposits in the normal tissues in cases of hypervitaminosis " $\mathrm{D}$ " with the hypercalcaemia that is produced by the overdose of this vitamin.

In this work, the increased number of the atretic follicles may be due to the arrested development of the growing follicles secondary to the calcium and haemosiderin depositions in them.

Holick and Adams (1998) reported that the ovarian follicles in rats started normal growth three weeks after the stoppage of the intake of high doses of vitamin " $\mathrm{D}$ " as a result of complete metabolism of its active form 1,25-dihydroxyvitamin " $\mathrm{D}$ " and its other metabolites. In our study the rats were left four weeks for recovery from the adverse effects of hypervitaminosis " $D$ " but their ovaries did not completely relieved especially with higher levels of hypervitaminosis. The needed duration for complete recovery requires further research.

It can be concluded from this work that the wide use of vitamin " $D$ " in different diseases should be done with great caution especially in women during the child bearing period due to its injurious effects on the ovaries. 


\section{SUMMARY}

Sixty-five adult female albino rats were used in this study. They were divided into three groups. Group I (five rats) were used as a control. Group 11 ; treated group (30 rats) were divided into three equal subgroups; $A, B$ and $C$, they received 2,3 and 4 doses of vitamin D respectively (12000 IU each) one week apart between each two doses and was sacrificed one week after the last dose. Group III ; recovered group (30 rats) divided into three equal subgroups $A, B$ and $C$, they received the same doses of vita$\min D$ as the three treated subgroups but they were left four weeks for recovery after the last given dose and then they were sacrificed. Five days before sacrifice vaginal smear was done daily at a fixed time of the day to detect the phase of estrous cycle. Rats of control group were sacrificed during diestrus phase.

Ovaries were dissected, examined and prepared for paraffin embedding. Serial sections were done, stained with Hx.\& E. and used for counting different types of ovarian follicles and corpora lutea by the image analyzer and examined by the light microscope for the structure of various follicles. Other sections were stained with Perl's Prussian blue stain for haemosiderin and Von Kossa stain for calcium.

In the treated rats vaginal smear examination showed disturbed estrus cycle in the form of sustained diestrus phase in $80 \%$ of rats of subgroup $A$. All rats $(100 \%)$ of subgroup B and C exhibited a sustained diestrus phase. Vaginal smear examination of the recovered rats showed various levels of improvement where all rats (100\%) of subgroup A, $60 \%$ of rats of subgroup $\mathrm{B}$ and only $30 \%$ of rats of subgroup $\mathrm{C}$ regained their normal estrus cycle. The remaining rats of subgroup $\mathrm{B}$ and $\mathrm{C}$ sustained the diestrus phase.

Histologically, the ovaries showed reduction in the number and size of the secondary and mature follicles with distorted configuration. Atretic follicles showed increase in their number. The cells of the granulosa and corona radiata of the secondary and mature follicles showed degenerative and apoptotic changes. Corpoa lutea were reduced in number and size with some apoptotic cells. Inflammatory signs in the form of congestion of the external surface of the ovary, medullary vessels and corpora lutea with dilated lymph vessels were observed. Areas of haemosiderin and calcium deposits were detected in the growing and atretic follicles as well as in the wall of the blood vessels. The severity of the previous manifestations was dose-dependent. Four weeks after the last dose, complete recovery was observed in subgroup $A$, while in subgroups $B$ and $C$ recovery was not complete. 


\section{REFERENCES}

1. Anderson, J.R. (1976): Muir's Textbook of Pathology. 10th ed., Edward Arnold Lto., London,pp . 247, 1649, 113-133.

2. Anderson, W.A. and Kissane, J.M. (1977): Pathology.7th ed., C.V. Mosby Company, USA, Vol. 1: 115-121

3. Braidman, I.P. and Anderson, D.C. (1985): Extraendocrine functions of vitamin D. J. Clin. Endocrinol., 23 : 445-460.

4. Dokoh, S.; Donalson, C.A.; Marion, S.L.; Pike, J.W. and Haussler, M.R. (1983): The ovary: A target organ for 1, 25-dihydroxyvitamin D3 . Endocrinol., 112(1) : 200-206.

5. Fife, R.S.; Sledge, G.W. and Proctor, C. (1997): Effects of vitamin D3 on proliferation of cancer cells in vitro. Cancer Lett., 120(1): 65-69.

6. Freeman, M.E. (1988): The Physiology of Reproduction. Knobil, E. and Neill, J. (eds.), Revan Press, New York, Vol. II: 1293-1295.

7. Funato, K.; Miyasawa, K.; Yaguchi, M.; Gotoh, A. and Ohyaashik, K. (2002): Combination of 22-oxa-1, 25-dihydroxyvitamin D3; a vitamin D derivative enhances cell differentiation in acute myeloid leukemia. Leukemia, 16(8): $1519-1527$.

8. Halloran, B.P. and DeLuca, H.F. (1980): Effect of vitamin D deficiency on fertility and reproductive capacity in the female rat. J. Nutr., 110: 15731580 .

9. Holick, M.F. and Adams, J.S. (1998): Metabolic Bone Disease and Clinically Related Disorders. Avioli, I.V. and Krane, S.M. (eds.), Academic Press, San Diego, California, pp. 124-164.

10. Horii, I.; Takizawa, S. and Tomoko, F. (1992): Effect of 1, 25 dihydroxyvitamin D3 on the female reproductive system in rats. J. Toxicol. Sci., 17: 91-105.

11. James, M.O. and Otto,W.N. (1975): Human Biochemistry . 9th ed., C. V. Mosby Company, USA.., Ch. VI: 571-574.

12. Johnson, J.A.; Grande, J.P.; Roche, P.C. and Kumar, R. (1996): Immunohistochemical detection and distribution of the 1,25dihydroxyvitamin D3 receptors in rat reproductive tissues. Histochem. Cell Biol, , 105(1): 7-15. 
13. Kumar, R.; Cohen, W.R.; Silva, P. and Epstein, E.H. (1979): Elevated 1,25-dihydroxyvitamin $D$ plasma levels in normal human pregnancy and lactation. J. Clin. Irest., $63: 342-344$.

14. Liu, W.; Asa, S.L.; Fantus, I.G.; Walfish, P.G. and Ezzat, S (2002): Vitamin $D$ arrests thyroid carcinoma cell growth and induces dephosphorylation. Am. J. Pathol., 160(2): 509-511.

15. Meehan, T.F. and DeLuca, H.F. (2002): The vitamin D receptor is necessary for 1,25-dihydroxyvitamin D3 to suppress experimental autoimmune encephalitis in mice. Arch. Biochem. Biophys., 408(2) : 200-204

16. Morita, T.; Awakura, T.; Shimada, A.; Umemura, T.; Nagai, T. and Haruna, A. (1995): Vitamin D toxicosis in cats: Natural outbreak and experimental study. J. Vet. Med. Sci., 57(5): 831-837.

17. Murray, R.K.; Granner, D.K.; Mayes, P.A. and Rodwell, V.W. (1988): Harper's Biochemistry. 21st ed., Appleton and Lange, California, Ch. 48: 497-501.

18. Nebel, M.D. and Ornstein, A. (1966): Effect of hypervitaminosis D2 on fertility and pregnancy in rats. Israel J. Med. Sci., 2: 14-21.

19. Papavasiliou, V.; Yu, J.; Rhim, J.; Goltzman, D. and Kremer, R. (1995): Vitamin $D$ analogues: New therapeutic agents for the treatment of squamous cancer and its associated hypercalcemia. Anticancer drugs, 6 (1): 101-108.

20. Uchiyama, H.; Susuki, T.; Koike, Y.; Ono, M.; Shirakawa, K.; Nagata, M. and Koniski, R. (1996 a): Reproductive and developmental toxicity studies of calcipotriol: (1) A fertility study in rats by subcutaneous administration. J. Toxicol. Sci., 21 S: 2389-2401.

21. Victor, P.E. (1993): Atlas of Histology with functional correlation. 7 th ed., Lea and Febiger, Philadelphia and London, pp. 274-281.

22. Vieth, R. (1999): Vitamin D supplementation, Vitamin $D$ concentration and safety. Am. J. Clin. Nutr, $69: 842-856$.

23. Woolf, N. (2000): Cell and tissue death and pigmentation and heterotropic calcification. The Basis of Pathology. 3rd ed., Saunders Company,
USA.., pp.39-45, 405-409. 
الملخص العربى

تأنيز زيادة فيتامين "د" على مبيض الفأر الأبيض البالغ

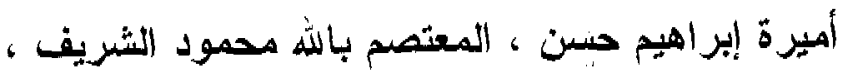

\section{مدحت محمد مرسي ، حنان داود بسيى}

قسم النشريح ، كلية الطب ، جامعة القاهرة

أجرى هذا البحث لدراسة ثأثنب زيادة فيتاهيز "د" على هبيض انتى الفئر

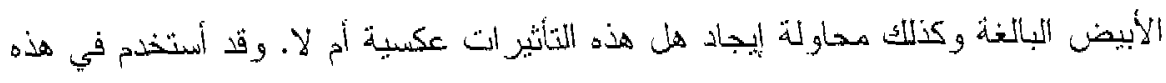

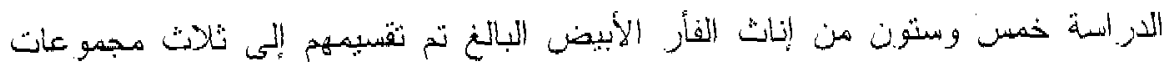

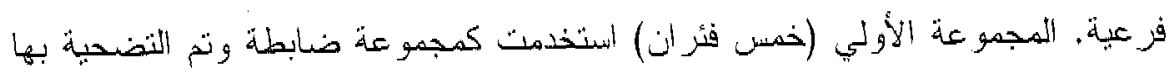

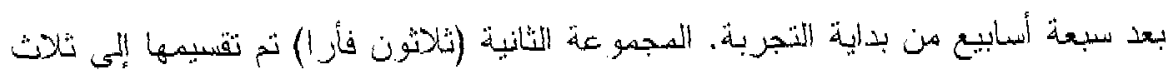

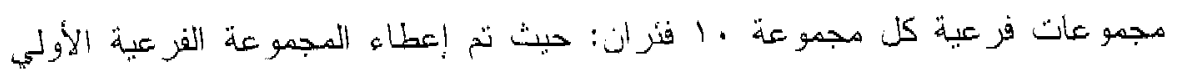

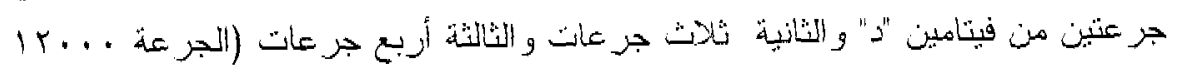

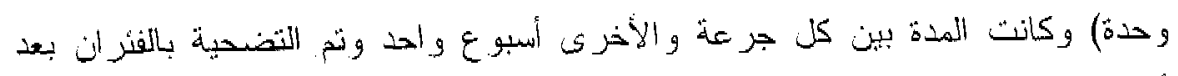

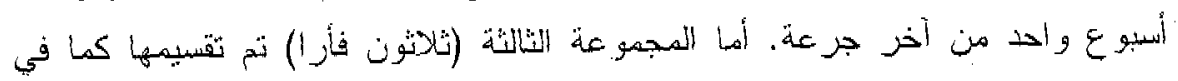

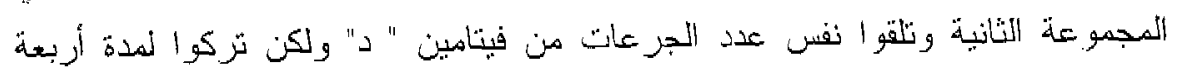

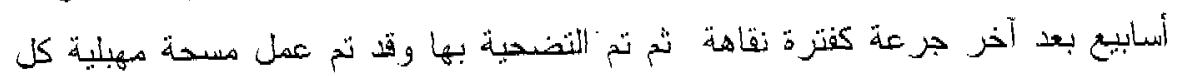

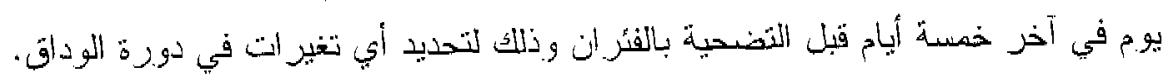

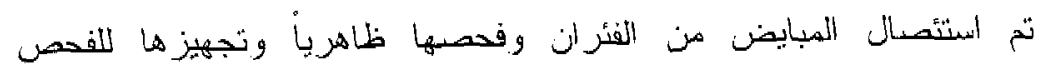

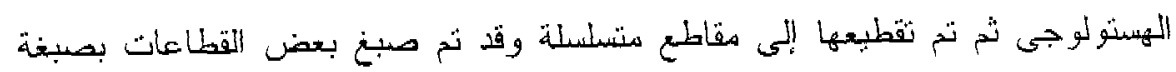

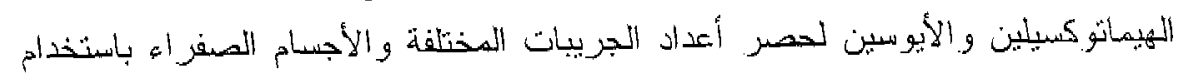

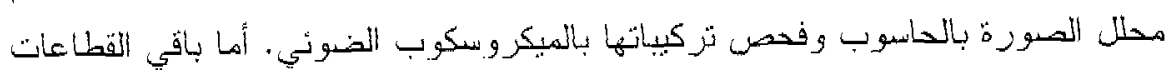

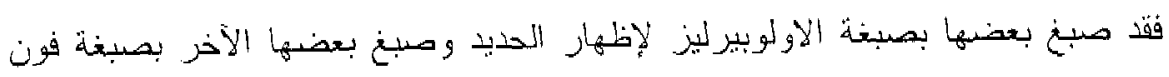

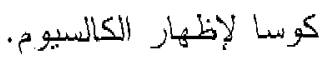


أوضحت نتانج المسحة المهلية في المجمو عة الثنانية حدوت نغير ات في الوداق

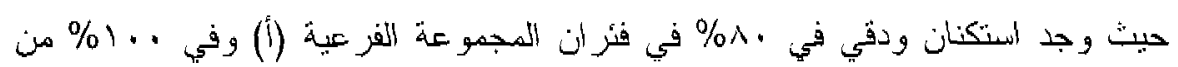

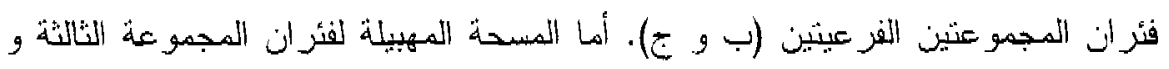

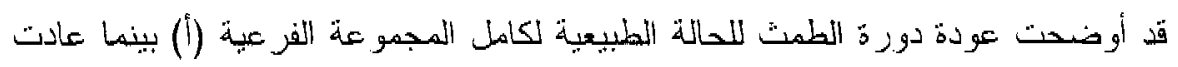

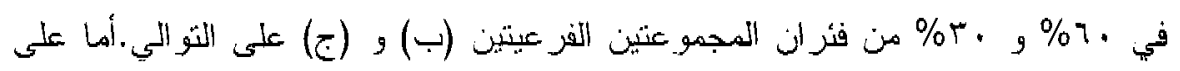

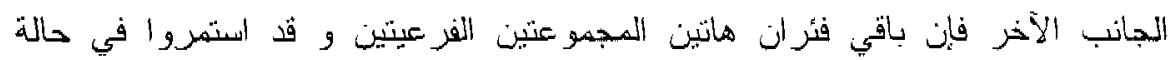
الانينكنان الودفي.

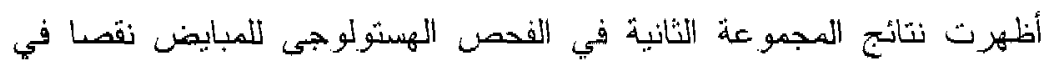
عدد وحجم الجريبات الثانوية والناضجة مع تغير شكلها وزيادة في عدد الجريبات

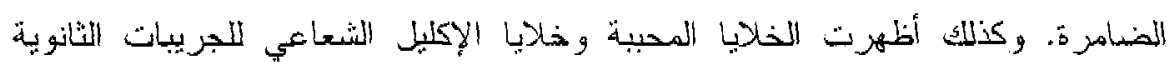

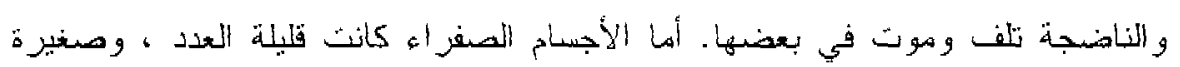

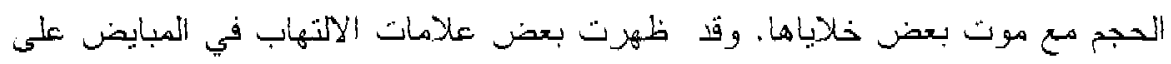

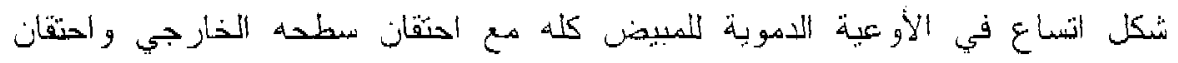

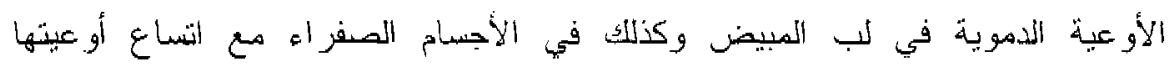

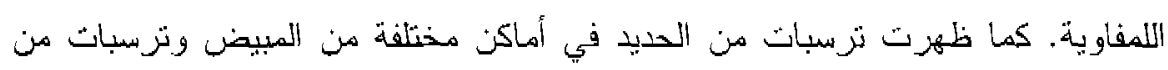

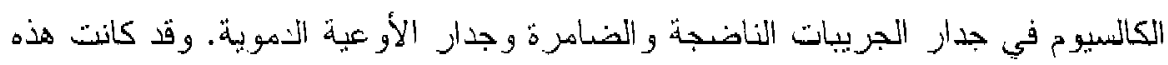

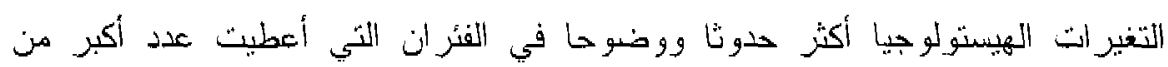

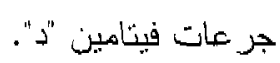
اختفت هذه الظواهر في المجمو عة الثاتلثة بعد فترة النقاهة في الفئران التي في

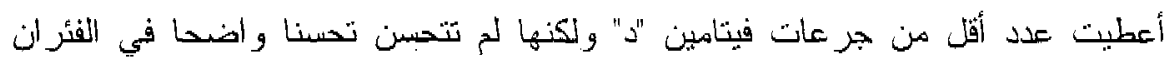
التي أعطيت عدد أكبر من الجرعات.

مجلة التشريح المصرية، VY (Y) ، يوليو ؛ . Tr 